DAKWATUNA

Jurnal Dakwah dan Komunikasi Islam

Volume 6, Nomor 2, Agustus 2020

p-ISSN: 2443-0617

e-ISSN: 2686-1100

\title{
Strategi Dakwah Kampung Qur'an Dalam Meningkatkan Nilai-Nilai Religius Di Desa Kalidilem Randuagung Lumajang
}

\author{
Aang Burhanuddin \\ Institut Agama Islam Syarifuddin Lumajang, Indonesia \\ Email: aang_burhanuddin85@gmal.com \\ Zainil Ghulam \\ Institut Agama Islam Syarifuddin Lumajang, Indonesia \\ Email: wanlamog@gmail.com
}

\begin{abstract}
Religious activities in the village of Kalidilem are already running but there are still some residents, especially teenagers, who get drunk and promiscuity. To overcome this problem a Kampung Qur'an program is formed. Kampung Qur'an is one of the Nahdlatul Ulama (NU, Islamic Organization) Lumajang programs that synergizes with $\mathrm{JQH}$ in the form of a missionary institution tasked with spreading the message of da'wah with the Qur'an. The village of the Qur'an was fully surrendered to the NU Autonomous Agency in charge of al-Qur'an. In the process of da'wah an important thing to consider is the da'wah strategy. This research uses descriptive qualitative method, with a phenomenological approach. Data collection techniques using interviews, observation and documentation. The conclusion of this study is the da'wah strategy used by the Qur'an Village there are 5 namely: 1) Sentimental strategy: conducting regular recitation, giving advice with good words, such as calling mad'u as "O my brothers, O my children" . 2) Rational strategy: invite people to discuss together. 3) Sensory Strategy: direct the practice of worship. 4) Ta'lim strategy: holding al-Qur'an illiteracy eradication program, development of tahfidzul quran, qiro'atul quran, art of calligraphy, organizing majlis of Qur'an interpretation and interpreneur of the Qur'an. 5) emulate the Prophet's strategy. The inhibiting factor of the preaching strategy of Kampung Qur'an is the lack of capable human resources in the field of alQur'an studies, understanding community psychology and having metacognitive abilities and philosophical thinking.
\end{abstract}

Keywords: Da'wah strategy, religious values, Kampung Qur'an.

\begin{abstract}
Abstrak
Kegiatan keagamaan yang ada di desa Kalidilem sudah berjalan namun masih ada beberapa warganya terutama yang masih berusia remaja ada yang mabuk-mabukan dan pergaulan bebas. Untuk mengatasi masalah tersebut maka dibentuklah program Kampung Qur'an. Kampung Qur'an
\end{abstract}


adalah salah satu program PCNU Lumajang yang bersinergi dengan JQH yang berbentuk lembaga dakwah bertugas menyebarkan pesan dakwahnya bernilaikan al-Qur'an. Kampung Qur'an secara penuh dipasrahkan kepada Badan Otonom NU yang membidangi khusus tentang al-Qur'an. Dalam proses dakwah hal penting yang harus diperhatikan adalah strategi dakwah. Penelitian ini menggunkan metode kualitatif deskriptif, dengan pendekatan fenomenologi. Teknik pengumpulan data menggunkan wawancara, observasi dan dokumentasi. Kesimpulan dari penelitian ini adalah strategi dakwah yang digunakan oleh Kampung Qur'an ada 5 yaitu: 1) Strategi sentimentil: mengadakan pengajian rutin, memberikan nasehat dengan perkataan yang baik, seperti memanggil mad'u dengan sebutan "wahai saudaraku, wahai anak-anakku". 2) Strategi rasional: mengajak masyarakat berdiskusi bersama. 3) Strategi Indrawi: mengajak langsung praktek ibadah. 4) Strategi ta'lim: mengadakan program pengentasan buta huruf al-Qur'an, pengembangan tahfidzul qur'an, qiro'atul qur'an, seni kaligrafi, menyelenggarakan majlis tafsir qur'an dan interpreneur al-Qur'an. 5) Meneladani strategi Rasulullah. Faktor penghambat strategi dakwah Kampung Qur'an yaitu Kurangnya SDM yang mampu dalam bidang kajian al-Qur'an, memahami psikologi masyarakat dan memiliki kemampuan metakognitif dan berfikir secara filosofis.

Kata Kunci : Strategi dakwah, nilai-nilai religius, Kampung Qur’an.

\section{PENDAHULUAN}

Islam merupakan agama yang diturunkan Allah kepada Nabi Muhammad yang mempunyai tujuan untuk menciptakan tata kehidupan masyarakat yang maju dan bermoral. ${ }^{1}$ Untuk mencapai hal tersebut maka perlu adanya dakwah. Dakwah adalah menyeru dan mengajak manusia ke jalan Allah dengan bijaksana, memberikan nasehat dan berdiskusi dengan baik², oleh karena itu dakwah memiliki tujuan untuk melakukan perubahan keyakinan, pengetahuan, dan perilaku sasaran dakwah sesuai dengan ajaran agama Islam. ${ }^{3}$ Berdakwah bisa dilakukan dengan berbagai metode, namun tetap memerhatikan aspek

\footnotetext{
${ }^{1}$ Ghazali Munir, “Al-Qur'an dan Realitas Sejarah Umat Manusia”, Jurnal At-Taqaddum, vol. 4, no. 1, (Juli 2012), 10.

${ }^{2}$ Ropingi El Ishaq, Pengantar Ilmu Dakwah (Studi Komprehensif Dakwah dari Teori ke Praktek) (Malang: Madani, 2016), 11.

3 Anggit Rizkianto, Manajemen Strategi Organisasi Dakwah (Studi pada Pimpinan Daerah 'Aisyiyah Surabaya) (Tesis, UINSA Surabaya, 2018), 1.
} 
interaksi antara pendakwah dan yang didakwahi, juga memberi atensi pada aspek kultural atau kondisi masyarakat setempat ${ }^{4}$. Salah satunya adalah metode dakwah qur'ani yaitu membangun masyarakat dengan memahami dan menguasai tafsir, sehingga dengan metode ini mad'u dapat mengetahui keistimewaan dari ayat-ayat al-Qur'an. Metode dakwah qur'ani dilakukan dengan mengajak masyarakat membaca, mengkaji, dan mengaplikasikan isi kandungan yang ada didalam al-Qur'an. ${ }^{5}$

Pecinta al-Qur'an, bukan hanya sekadar sayang tapi dipelajari, difahami, diamalkan dan diajarkan. ${ }^{6}$ Sebagai bukti cintanya mereka akan semakin bersemangat membaca al-Qur'an setiap waktu, mempelajari isi kandungan alQur'an dan memahaminya. Selanjutnya, akan mengamalkan al-Qur'an dalam kehidupan sehari-hari, baik hubungan dengan Allah maupun dengan lingkungan disekitarnya.7 Dalam kehidupan modern saat ini semuanya serba kompleks, dimana ilmu pengetahuan dan teknologi begitu canggih, sehingga mengakibatkan perkembangan globalisasi terjadi secara massif. Budaya, sosial, ekonomi, politik, pendidikan, berjalan dan berkembang secara berkelindan. ${ }^{8}$ Kemajuan teknologi tidak selamanya memberikan dampak positif akan tetapi ada juga dampak negatifnya. Adanya kemajuan dalam segala aspek kehidupan justru banyak yang mengabaikan tuntutan agama sehingga menyebabkan

\footnotetext{
${ }^{4}$ Rio Febriannur Rachman. (2018). Dakwah Intraktif Kultural Emha Ainun Nadjib. Jurnal Spektrum Komunikasi, 6(2), 1-9.

${ }^{5}$ Khairunnisa, Metode Dakwah Qur'ani KH. Ahmad Hadlor Ihsan dalam Membina Kemaslahatan Ummat di Kelurahan Mangkang Kulon Kecamatan Tugu Kota Semarang, Skripsi (Semarang: UIN Walisongo, 2018), 38.

6 Nining, wawancara, Randuagung, Kamis, 30 Januari 2020, Hakikat Pecinta al-Qur'an.

7 Fahrur Razi, wawancara, Randuagung, kamis, 30 Januari 2020, Proses Mempelajari, Memahami,dan Mengamalkan al-Qur'an.

8 Permasalahan budaya, sosial, ekonomi, politik, pendidikan khususnya keagamaan di era globalisasi semakin menjadi-jadi. Kualitas keberagamaan masyarakat cenderung melemah akibat perubahan nilai yang berkembang. Solidaritas Islam sebagai nilai islami dalam bermasyarakat mulai berhadapan dengan kecenderungan sikap individualistik akibat kemajuan dunia usaha yang mengacu pada watak kompetitif. Nilai ekonomispun semakin dominan sehingga berpengaruh besar terhadap berkembangnya etos ikhtiar yang pada gilirannya yang akan menghilangkan sikap tawakal dan keimanan menurut buku KH. MA. Sahal Mahfudh, Nuansa Fiqh Sosial (Yogyakarta: LkiS, 1994), 117.
} 
pegeseran nilai-nilai religius yang semakin lama semakin menipis. Akibatnya banyak yang hanyut dalam kemajuan zaman tanpa memperhatikan lagi ajaran agama dalam kehidupannya. Hubungan manusia juga cenderung impersonal, tidak akrab lagi antara yang satu dengan yang lainnya. Persaudaraan menjadi tidak penting dalam kehidupan sehari-hari, religiusitas terabaikan. Orientasi manusia hanya terfokus pada soal materi. ${ }^{9}$ Masalah mulai bermunculan dari berbagai hal. Satu permasalahan tidak hanya dipicu oleh satu aspek saja sehingga penyelesaiannyapun memerlukan pendekatan secara multidisiplin. ${ }^{10}$

Rektor Institut Perguruan Tinggi IImu Al-Qur'an (PTIQ) Jakarta, Prof. Dr. KH. Nasaruddin Umar mengatakan bahwa perkembangan globalisasi juga berpengaruh terhadap jumlah generasi muslim yang mampu membaca dan mengkaji al-Qur'an. Berdasarkan hasil riset Badan Pusat Statistik (BPS) tahun 2013 menyebutkan dari total populasi umat Islam di Indonesia sekitar 54\% tidak mampu membaca dan mengkaji al-Qur'an. Sementara hasil riset dari Institut IImu Al-Qur'an (IIQ) sekitar 65\% umat Islam di Indonesia masih buta aksara alQur'an. ${ }^{11}$ Bahkan yang lebih memprihatinkan adalah adanya umat muslim yang hingga masa remaja tidak pernah bersentuhan dengan al-Qur'an sama sekali. Hal ini disebabkan oleh krisis moral, pergaulan bebas para remaja, dan sibuk dengan media sosialnya masing-masing. Di tengah problematika kehidupan beragama ini, umat juga dihadapkan dengan berbagai persoalan aqidah dan ahlak yang mengharuskan umat mengatasi persoalan tersebut menggunakan beberapa strategi yang tepat. Sebagaimana pemerintah selama ini, di level

\footnotetext{
${ }_{9}$ Apin Arsah, Pengaruh Globalisasi Terhadap Nilai Agama Islam (Palembang: UNMUH Palembang, 2015), 49.

10 Muhammad Ngafifi, "Kemajuan Teknologi dan Pola Hidup Manusia dalam Perspektif Sosial Budaya”, Jurnal Pembangunan Pendidikan: Fondasi dan Aplikasi, vol. 2, no. 1 (2014), 24.

11 Nasrullah Nurdin, Generasi Emas Santri Zaman Now (Jakarta: PT. Elex Media Komputindo, 2019), 75 .
} 
pusat, provinsi, maupun kabupaten/kota, yang menciptakan inovasi di bidang ekonomi ${ }^{12}$, sosial ${ }^{13}$, pendidikan ${ }^{14}$, dan lain sebagainya demi kemaslahatan umat.

Lembaga dakwah juga harus tampil secara aktual, faktual dan konseptual. Aktual dalam arti memecahkan masalah kekinian yang hangat di masyarakat, faktual dalam arti kongkret serta nyata dan konseptual dalam arti relevan dan menyangkut problema yang sedang dihadapi masyarakat. ${ }^{15}$

Melihat kondisi masyarakat yang seperti ini, maka PCNU Lumajang bersinergi dengan Jam'iyatul Qurro' Wal huffadh (JQH) membentuk program dakwah al-Qur'an berbasis lingkungan, dan komunitas yang berada di daerah terpencil yakni Kampung Qur'an. Pendirian program Kampung Qur'an ini juga muncul dari permintaan masyarakat setempat agar diadakan kajian bagi para orang tua di atas umur 40 tahun khususnya pembelajaran baca tulis al-Qur'an. Kampung Qur'an memiliki sebuah tujuan untuk membentuk masyarakat yang mereka bina memiliki nilai-nilai berlandaskan al-Quran baik dari bidang ekonomi, pendidikan, sosial dan budaya. Dalam pelaksanaannya Kampung Qur'an dipasrahkan secara penuh kepada Badan Otonom NU yang membidangi khusus dalam bidang al-Qur'an. ${ }^{16}$

Kampung Qur'an memerlukan sebuah strategi ${ }^{17}$ yang bisa bertahan hingga beberapa tahun kedepan. Tanpa menggunakan strategi yang tepat, dakwah Islam tidak dapat dijalankan dengan baik dan tentu tidak akan memperoleh hasil yang maksimal. ${ }^{18}$ Al-Bayanuni mendefinisikan strategi

\footnotetext{
${ }^{12}$ Rio Febriannur Rachman. (2019). Optimalisasi Media Digital Berbasis Kemaslahatan Umat dalam Program Pahlawan Ekonomi Surabaya. IQTISHODUNA: Jurnal Ekonomi Islam, 8, 273-292.

13 Rio Febriannur Rachman. (2019). Optimalisasi Teknologi Komunikasi Informasi Command Center Bagi Efektifitas Tenaga Kesejahteraan Sosial Kecamatan. Dakwatuna: Jurnal Dakwah dan Komunikasi Islam, 5(2), 170-180.

${ }^{14}$ Rio Febriannur Rachman. (2020). Kebijakan Pendidikan Anak Berkebutuhan Khusus Di Surabaya Dalam Perspektif Islam. Bidayatuna: Jurnal Pendidikan Guru Mandrasah Ibtidaiyah, 3(01), 125-143.

15 Muhammad Munir, Manajemen Dakwah (Jakarta: Kencana, 2003), 102.

16 Ustad Abdul Halim, wawancara, Randuagung, Senin, 27 Januari 2020, Profil Kampung Qur'an. 17 Strategi adalah metode, siasat, dan taktik yang digunalkan dalam kegiatan dakwah. Menurut buku Asmuni Syukir, Dasar-Dasar Strategi Dakwah Islam (Surabaya: Al-Ikhlas, 1983), 32.

18 Ropingi El Ishaq, Pengantar Ilmu Dakwah (Malang: Madani, 2016), 104.
} 
dakwah (manahij al-da'wah) sebagai ketentuan-ketentuan dakwah dan rencana-rencana yang dirumuskan untuk kegiatan dakwah. Menurut M. Ali Aziz strategi dakwah adalah perpaduan perencanaan dan manajemen untuk mencapai suatu tujuan. Strategi tidak hanya berfungsi sebagai peta jalan yang harus ditempuh, tapi juga berisi taktik operasionalnya. ${ }^{19}$ Metode dan media dakwah yang sesuai dengan masyarakat akan membuat tujuan tercapai sekaligus mengasah simpati warga pada semua ajaran Islam, serta menggerus asumsi bahwa agama ini sukar diimplementasikan secara menyeluruh dan menghilangkan ketakutan-ketakutan yang mungkin tumbuh karena mengganggap Islam adalah agama yang rumit ${ }^{20}$.

Dalam kitab Al-Madkhal ila 'ilmi ad-dakwah karya Muhammad Abu Al-Fath Al-Bayanuni yang dikutip oleh M. Ali Aziz mengatakan bahwasanya strategi dakwah meliputi tiga hal yaitu strategi sentimentil, strategi rasional dan strategi indrawi. ${ }^{21}$ Dalam mencapai sebuah tujuan srategi dakwah harus memiliki taktik dan pendekatan yang harus dilakukan sesuai dengan kondisi masyarakat dan perkembangan zaman yang ada22. Dengan adanya strategi dakwah sebuah organisasi maupun lembaga dakwah dapat berfikir secara konseptual dan bertindak secara sisematik. ${ }^{23}$ Dalam konteks umat Islam saat ini yang diperlukan adalah strategi dakwah yang berorientasi transformasi sosio kultural dengan multimedia dengan sesuatu pendekatan partisipatif. ${ }^{24}$

\footnotetext{
${ }^{19}$ M. Ali Aziz, Ilmu Dakwah (Jakarta: Kencana, 2004), 201.

${ }^{20}$ Rio Febriannur Rachman. (2018). Perspektif Karen Armstrong Tentang Islamofobia Di Media Barat. Dakwatuna: Jurnal Dakwah dan Komunikasi Islam, 4(2), 282-291.

${ }^{21}$ M. Ali Aziz, Ilmu Dakwah (Jakarta: Kencana, 2004), 300.

${ }^{22}$ Faiwotul Mala. (2017). “E-Dakwah”: Tinjauan Awal Kontestasi Islam, Dakwah, Dan Internet. Dakwatuna: Jurnal Dakwah dan Komunikasi Islam, 3(1), 12-26.

${ }^{23}$ Lembaga dakwah harus mempunyai sebuah konsep agar dakwah yang dilakukan berjalan dengan lancar.

24 Pendekatan partisipatif yaitu melibatkan sasaran dakwah dalam perencanaan dakwah bahkan dalam penggalian permasalahan dan kebutuhan. Dengan pendekatan inilah akan tumbuh dinamisasi ide dan gagasan baru dimana para da'i berperan sebagai pemandu dalam dialog-dialog keberagamaan yang muncul dalam mencari alternatif pemecahan masalah. Menurut Jurnal Pradipto, Pengaruh Komunikasi Persuasif dalam Meningkatkan Kesadaran Solidaritas Anggota Scooter Moods Bogor Indonesia, Jurnal Komunikatio, vol. 3, No. 2, (Oktober 2017), 63.
} 


\section{PERMASALAHAN}

Proses strategi dakwah Kampung Qur'an sangat berpengaruh terhadap lingkungan di sekitarnya. Pada saat ini semenjak dibentuknya Kampung Qur'an masyarakat Kalidilem begitu antusias mengikuti semua kegiatan yang dilaksanakan di Kampung Qur'an mulai dari usia anak-anak sampai dewasa serta meningkatnya nilai-nilai keagamaan seperti aqidah, ibadah, dan ahlak. Berdasarkan latar belakang dan melihat beberapa fenomena diatas peniliti tertarik ingin melakukan penelitian mengenai "Strategi Dakwah Kampung Qur'an dalam Meningkatkan Nilai-Nilai Religius di Desa Kalidilem Randuagung Lumajang".

\section{METODE PENELITIAN}

Penelitian ini menggunakan metode kualitatif dengan pendekatan fenomenologi. Peneliti mengambil metode kualitatif karena sangat tepat untuk strategi dakwah dan sosiologi keagamaan yang mampu membahasakan serta mendeskipsikan perilaku juga interaksi sebagai fenomena yang unik. ${ }^{25}$ Penelitian ini membahas tentang strategi dakwah Kampung Qur'an dalam meningkatkan nilai-nilai religius. Peneliti menganalisis topik tersebut dengan sumber data yang berasal dari data primer yaitu ketua PCNU Lumajang, ketua dan wakil JQH NU Lumajang, ketua Kampung Qur'an, pengurus Kampung Qur'an dan masyarakat Kampung. Sumber-sumber lain yang dijadikan acuan adalah skripsi, jurnal, dan tesis. Teknik yang dilakukan adalah melakukan observasi, wawancara, dan dokumentasi di lapangan.

\section{PEMBAHASAN}

Problematika di era globalisasi ini semakin meningkat, mulai dari masalah agama, ekonomi, pendidikan, sosial dan budaya. Problematika yang

\footnotetext{
${ }^{25}$ Moh. Kasiram, Metodologi Penelitian Kualitatif-Kuantitatif (Malang: UIN Maliki Press, 2010), 121.
} 
sering terjadi adalah krisisnya ahlak dan kegiataan keagamaan mulai menurun. Masyarakat yang belum bisa membaca al-Qur'an sudah mulai malas karena merasa capek setelah bekerja, remaja di era milenial banyak yang hobi cangkru'an ${ }^{26}$, ngamen, mabuk-mabukan, dan anak-anak lebih mencintai gadget daripada mengaji. Remaja bertindak seperti itu bukan tanpa ada alasan. Ada beberapa faktor yang menyebabkan ahlak para remaja menurun diantaranya adalah kurangnya pengawasan dan bimbingan dari orang tua, serta pergaulan bebas yang tidak terkontrol. Untuk mengatasi hal tersebut maka muncullah gagasan dari Alm. Drs. Syamsul Huda, M.Pd untuk membentuk program dakwah al-Qur'an berbasis kawasan, lingkungan, dan komunitas yang berada di daerah terpencil yang disebut dengan Kampung Qur'an.

Membahas mengenai dakwah tidak akan terlepas dari strategi dakwah yang mana berperan penting untuk berjalannya kegiatan dakwah dengan baik, salah satunya adalah strategi dakwah al-Quran. Strategi dakwah merupakan cara atau metode yang efektif mengajak manusia kepada ajaran Allah sehingga terealisasilah kehendak-kehendaknya di muka bumi. Menurut Abu Zahra yang dikutip oleh Acep Aripudin Strategi dakwah adalah perencanaan, penyerahan kegiatan dan operasi dakwah Islam yang dibuat secara rasional untuk mencapai tujuan-tujuan Islam yang meliputi seluruh dimensi kemanusiaan. ${ }^{27}$ Strategi dakwah al-Qur'an saat ini mengalami transformasi, tidak hanya terbatas di lingkup kalangan pesantren saja melainkan telah mengalami perkembangan yang signifikan. Konsep strategi dakwah yang dibangun oleh Kampung Qur'an adalah strategi yang bisa membentuk masyarakat memiliki nilai-nilai berlandaskan al-Qur'an baik dari bidang ekonomi, pendidikan, sosial, dan budaya. ${ }^{28}$ Keberhasilan ini tidak akan tercapai tanpa adanya sebuah strategi, kerjasama dan solidaritas antara masyarakat, pengurus, dan ketua Kampung

\footnotetext{
${ }^{26}$ Nongkrong.

${ }^{27}$ Acep Aripudin dan Syukriadi Syambas, Dakwah Damai: Pengantar Dakwah Antar Budaya (Bandung: PT. Remaja Rosdakarya, 2007), 138.

${ }^{28}$ Ustad Abdul Halim, wawancara, Randuagung, Senin, 27 Januari 2020, Profil Kampung Qur’an.
} 
Qur'an karena Kampung Qur'an memiliki harapan besar agar kualitas iman dan ahlak masyarakat meningkat. ${ }^{29}$

Strategi dakwah Kampung Qur'an ini sesuai dengan apa yang ada di dalam kitab Al-Madkhal ila 'ilmi ad-dakwah karya Muhammad Abu Al-Fath AlBayanuni yang dikutip oleh M. Ali Aziz yang mengatakan bahwasanya strategi dakwah meliputi tiga hal yaitu strategi sentimentil, strategi rasional dan strategi indrawi. ${ }^{30}$ Namun selain strategi tersebut Kampung Qur'an menggunakan strategi lain yaitu menggunakan strategi ta'lim dan menggunakan azas strategi dakwah yaitu azas sosiologis dan psikologis agar ketika berdakwah mengetahui kondisi, situasi, dan karakter masyarakat. Kampung Qur'an juga melakukan pendekatan sosial melalui program pendampingan masyarakat, hal ini dilakukan agar mampu memberikan ketertarikan pada masyarakat untuk lebih dekat berinteraksi bersama al-Qur'an.

1. Strategi Sentimentil

Kegiatan keagaamaan masyarakat desa Kalidilem sebelum adanya Kampung Qur'an menurun terutama para remaja yang hanya sibuk dengan nongkrong yang tidak ada gunanya. Jika kondisi seperti ini tidak diarahkan dikhawatirkan akan lebih terjerumus pada hal-hal yang negatif. Maka dari itu Kampung Qur'an menggunakan strategi sentimentil dengan menggerakkan hati dan perasaan, memberikan nasehat yang baik dan perkataan yang lembut. Kegiatan yang diadakan oleh Kampung Qur'an yang sesuai dengan strategi sentimentil yaitu mengadakan pengajian rutin, bertausiah, memberikan nasehat dengan perkataan yang baik dan lemah lembut kepada masyarakat, seperti memanggil mereka dengan sebutan "wahai saudaraku, wahai anak-anakku", memberikan motivasi dan setiap kali ada masyarakat yang meminta bantuan dihargai dan dilayani dengan baik.

2. Strategi Rasional

\footnotetext{
29 Abdul Basit, Filsafat Dakwah (Jakarta: Raja Grafindo Persada, 2013), 20.

${ }^{30}$ M. Ali Aziz, Ilmu Dakwah (Jakarta: Kencana, 2004), 300.
} 
Strategi rasional yang digunakan Kampung Qur'an agak sedikit berbeda dengan apa yang dikatakan dalam teori strategi dakwah AlBayanuni yang mengatakan bahwa sasaran strategi rasional adalah Orangorang yang ingkar pada hal yang nyata dan dapat diterima akal sehat, Orangorang yang menuhankan akal dan pemikirannya, Orang-orang yang bijaksana yang jauh dari fanatisme karena pandangannya dan tidak bias oleh pandangan-pandangan khusus, Ahlu subhat (penyebar berita palsu) dan yang diperdaya oleh kebathilan dan fitnah. Kampung Qur'an bukan melakukan perdebatan atau berdiskusi dengan orang yang bijaksana, berintelektual dan kritis namun Kampung Qur'an mengajak masyarakat terutama remaja berdiskusi bersama.

3. Strategi Indrawi

Hal yang biasa dilakukan oleh masyarakat jika diberikan nasehat atau solusi terkadang mereka memberikan bantahan, jika ini terjadi maka strategi indrawi harus dilakukan yakni melakukan praktek keagamaan secara langsung atau memberikan gambaran yang bisa meyakini dan menjawab keraguan masyarakat, seperti menggunakan audio visual dengan menyiarkan film-film Islami, menjelaskan sifat-sifat Allah, serta praktek ibadah, seperti wudlu', sholat, dan haji. Dakwah yang menjadikan indra manusia sebagai sasaran, termasuk di dalamnya elemen audio visual, memiliki kekuatan tersendiri dan implementatif31.

4. Strategi Ta'lim

Kampung Qur'an membuat kurikulum yang dilakukan secara formal, sistematis dan bertahap dengan membuat beberapa program yaitu:

a. Pengentasan buta huruf al-Qur'an dari usia dini sampai lansia.

b. Pengembangan Tahfidzul Qur'an sebagai program lanjutan setelah mampu membaca dan menulis al-Qur'an.

${ }^{31}$ Muhammad Abdul Halim Sidiq. (2016). DAKWAH DENGAN AUDIO VISUAL (Efektifitas Dakwah Islamiyah Mengunakan Media Teknologi Audio Visual Pada Masyarakat). Dakwatuna: Jurnal Dakwah dan Komunikasi Islam, 2(2), 91-106. 
c. Pengembangan Qiro'atil Qur'an dengan menggunakan metode dan pembinaan dari JQH NU Lumajang.

d. Pengembangan seni kaligrafi Qur’an.

e. Menyelenggarakan majlis tafsir Qur'an yang dilaksanakan dalam satu minggu sekali.

f. Pengembangan interpreneur al-Qur'an.

5. Meneladani Strategi Dakwah Rasulullah

Selain strategi dakwah tersebut Ustad Abdul Halim sendiri dalam bersikap kepada mad'unya mengambil teladan dari apa yang di contohkan oleh Nabi Muhammad SAW yang disebutkan dalam al-Qur'an surat A'basa yaitu:

a. Memberikan Penghargaan yang Sama

Dalam berdakwah seseorang harus memberikan penghargaan yang sama yaitu tidak membeda-bedakan antara yang satu dengan yang lainnya. Sesama manusia harus saling menghormati dan menghargai. Dalam kehidupan, manusia adalah mahluk sosial yang tidak terlepas dari orang lain yang saling berhubungan dan berhadapan dengan penuh keanekaragaman dari kalangan bawah maupun atas. Semua itu sama dihadapan Allah yang membedakan hanyalah ketaqwaan dan hatinya. Hal ini tersirat dalam al-Qur'an surat al-Hujurat ayat 13 yang artinya:

"Hai manusia sesungguhnya Kami menciptakan kamu dari seorang laki-laki dan perempuan dan menjadikan kamu bersukusuku dan berbangsa-bangsa supaya kamu saling mengenal. Sesungguhnya orang yang paling mulia diantara kamu disisi Allah ialah orang yang paling taqwa diantara kamu. Sesungguhnya Allah Maha mengetahui lagi Maha Mengenal."32

\footnotetext{
${ }^{32}$ Al-Qur'an, 49:13.
} 
b. Tidak Berfikir Negatif Kepada Orang Lain

Dalam berdakwah tidak boleh berprasangka buruk kepada mad'u. Seorang muslim tidak dibenarkan meyakini dan mempercayai sesuatu yang didasarkan pada prasangka. Allah SWT juga memerintahkan manusia untuk menjauhi prasangka buruk. Sebagaimana firman Allah dalam alQur'an surat al-Hujuraat ayat 12 yang artinya:

"Hai orang-orang yang beriman jauhilah purba sangka (kecurigaan) karena sebagian dari purba sangka itu adalah dosa. Dan janganlah mencari-cari keburukan dan janganlah menggunjingkan satu sama lain. Adakah seseorang diantara kamu yang suka memakan daging saudaranya yang sudah mati?. Maka tentulah kamu merasa jijik kepadanya. Dan bertaqwalah kepada Allah. Sesungguhnya Allah maha penerima taubat lagi maha penyayang." 33

c. Bersikap Cermat dan Berhati-Hati dalam Mengambil Suatu Tindakan

Cermat merupakan sikap berhati-hati dalam menjalankan sesuatu, tidak tergesa-gesa dan cerobah dalam melakukan pekerjaan. Hal ini dilakukan agar tidak terjadi kesalahan dalam mengerjakan suatu tindakan. Jadi dalam berdakwah harus memperhatikan dengan baik persiapanpersiapan yang harus ada sebelum berdakwah baik itu kondisi dan situasi mad'u, metode, maupun strategi dakwah yang digunakan.

Faktor Penghambat Strategi Dakwah Kampung Qur'an dalam Meningkatkan Nilai-Nilai Religius

a. Kurangnya SDM yang mampu dalam bidang kajian al-Qur'an, memahami psikologi masyarakat, serta memilki kemampuan mtakognitif dan berfikir secara filosofis.

33 Al-Qur'an, 49:12. 
b. Meskipun beberapa strategi sudah dilakukan namun masih ada masyarakat terutama para remaja yang belum sadar.

c. Minimnya pendanaan.

d. Belum terlaksananya sinergitas dengan LAZIZNU dan Lakpesdam.

\section{PENUTUP}

Adapun hasil analisis strategi dakwah Kampung Qur'an dalam meningkatkan nilai-nilai religius menghasilkan sebuah konsep strategi dakwah yang mudah difahami dan di praktekkan dalam kehidupan sehari-hari. Strategi dakwah al-Qur'an saat ini mengalami transformasi, tidak hanya terbatas di lingkup kalangan pesantren saja melainkan telah mengalami perkembangan yang signifikan, seperti program Kampung Qur'an. Kampung Qur'an tidak hanya berhenti dalam konteks keilmuan saja, melainkan juga membentuk dan mempengaruhi pola pikir masyarakat melalui al-Qur’an dengan cara melakukan pendekatan sosial melalui program pendampingan masyarakat, hal ini dilakukan agar mampu memberikan ketertarikan pada masyarakat untuk lebih dekat berinteraksi bersama al-Qur'an.

\section{REFERENSI}

Aripuddin, Acep. 2007. Dakwah Damai Pengantar Dakwah Antar Budaya. Bandung: PT. Remaja Rosdakarya.

Arsah, Apin. 2015. Pengaruh Globaliasi Terahadap Nilai Agama Islam. Palembang: UNMUH Palembang.

Aziz, Ali. 2004. Ilmu Dakwah. Jakarta: Kencana.

Basit, Abdul. 2013. Filsafat Dakwah. Jakarta: Raja Grafindo Persada.

El Ishaq, Ropingi. 2016. Pengantar Ilmu Dakwah. Malang: Madani.

Kasiram, Muhammad. 2010. Metodologi Penelitian Kualitatif-Kuantitatif. Malang: UIN Maliki Press. 
Khoirunnisa. 2018. Skripsi. Metode Dakwah Qur'ani KH. Ahmad Hadlor Ihsan dalam Membina Kemaslahatan Ummat di Kelurahan Mangkang Kulon Kecamatan Tugu Kota Semarang. Semarang: UIN Walisongo.

Mahfudz, Sahal. 1994. Nuansa Fiqh Sosial. Yogyakarta: LkiS.

Mala, F. (2017). “E-Dakwah”: Tinjauan Awal Kontestasi Islam, Dakwah, Dan Internet. Dakwatuna: Jurnal Dakwah dan Komunikasi Islam, 3(1), 12-26.

Munir, Ghazali. “Al-Qur'an dan Realitas Sejarah Umat Manusia”. Jurnal AtTaqaddum. vol. 4, no. 1, (Juli 2012).

Munir, Muhammad. 2003. Metode Dakwah. Jakarta: Kencana.

Ngafifi, Muhammad. “Kemajuan Teknologi dan Pola Hidup Manusia dalam Perspektif Sosial Budaya”. Jurnal Pembangunan Pendidikan: Fondasi dan Aplikasi. vol. 2, no. 1, (2014).

Nurdin, Nasrullah. 2019. Generasi Emas Santri Zaman Now. Jakarta: PT. Elex Media Komputindo.

Pradipto. “Pengaruh Komunikasi Persuasif dalam Meningkatkan Kesadaran Solidaritas Anggota Scooter Moods Bogor". Jurnal Komunikatio. vol. 3, no. 2, (Oktober 2017).

Rachman, R. F. (2018). Dakwah Intraktif Kultural Emha Ainun Nadjib. Jurnal Spektrum Komunikasi, 6(2), 1-9.

Rachman, R. F. (2018). Perspektif Karen Armstrong Tentang Islamofobia Di Media Barat. Dakwatuna: Jurnal Dakwah dan Komunikasi Islam, 4(2), 282-291.

Rachman, R. F. (2019). Optimalisasi Teknologi Komunikasi Informasi Command Center Bagi Efektifitas Tenaga Kesejahteraan Sosial Kecamatan. Dakwatuna: Jurnal Dakwah dan Komunikasi Islam, 5(2), 170180.

Rachman, R. F. (2019). Optimalisasi Media Digital Berbasis Kemaslahatan Umat dalam Program Pahlawan Ekonomi Surabaya. IQTISHODUNA: Jurnal Ekonomi Islam, 8, 273-292. 
Rachman, R. F. (2020). Kebijakan Pendidikan Anak Berkebutuhan Khusus Di Surabaya Dalam Perspektif Islam. Bidayatuna: Jurnal Pendidikan Guru Mandrasah Ibtidaiyah, 3(1), 125-143.

Rizkianto, Anggit. 2018. Tesis. Manajemen Strategi Organisasi Dakwah (Studi pada Pimpinan Daerah 'Aisyiyah Surabaya). Surabaya: UINSA Surabaya.

Sidiq, M. A. H. (2016). Dakwah Dengan Audio Visual (Efektifitas Dakwah Islamiyah Mengunakan Media Teknologi Audio Visual Pada Masyarakat). Dakwatuna: Jurnal Dakwah dan Komunikasi Islam, 2(2), 91106. 